\title{
Effect of Cooling Rate on the Microstructure of a Pressure Vessel Steel
}

\author{
Arpan Das $^{1} \cdot$ Saurav Sunil ${ }^{1} \cdot$ Rajeev Kapoor ${ }^{1}$ \\ Received: 27 March 2019 / Revised: 18 September 2019 / Accepted: 15 October 2019 / Published online: 7 November 2019 \\ (c) ASM International 2019
}

\begin{abstract}
The present article thoroughly explores the effect of cooling rate on various microstructural features of a reactor pressure vessel steel (20MnMoNi55). For this, dilatometric experiments were performed at different cooling rates. Optical microscopy and electron backscatter diffraction were used to measure different microstructural parameters. Continuous cooling from 0.15 to $0.3{ }^{\circ} \mathrm{C} / \mathrm{s}$ revealed ferrite and bainite; only bainite is seen from 1 to $2{ }^{\circ} \mathrm{C} / \mathrm{s}$, both bainite and martensite were found in the regime 5 to $15{ }^{\circ} \mathrm{C} / \mathrm{s}$, and complete martensitic transformation was observed at cooling rate $20^{\circ} \mathrm{C} / \mathrm{s}$ and above. With increase in cooling rate, the fraction of low angle boundary decreased and that of high angle boundary increased. The nature of grain size distribution was found to be cooling rate sensitive.
\end{abstract}

Keywords $20 \mathrm{MnMoNi55}$ steel $\cdot$ Cooling rate $\cdot$ Grain size $\cdot$ Electron backscatter diffraction $\cdot$ Misorientation

\section{Introduction}

Nuclear reactor safety requires research to critically assess the structural integrity of pressure vessels and their parts [1]. The safety and life extension of power plants are important issues now-a-days. A pressure vessel is one of the most important components in a pressurized water reactor (PWR), containing the core and coolant and also providing radiation shielding from the intensely radioactive reactor core [2]. Thus, the service life of a nuclear power plant depends on pressure vessels. The alloys used as materials for the pressure vessel require excellent tensile properties (high strength resistant), toughness, weldability, and good resistance to irradiation embrittlement over a service period and should have the ductile-to-brittle transition temperature (DBTT) significantly beneath the operating service temperature [3].

Nuclear reactor pressure vessels are usually made of low-alloy bainitic steels. One such steel is 20MnMoNi55 which after quenching and tempering consists of bainite with cementite $\left(\mathrm{Fe}_{3} \mathrm{C}\right)$ and $\mathrm{M}_{2} \mathrm{C}$ precipitates [4]. Significant research has already been documented on different metallurgical aspects (i.e., physical metallurgy, fracture) of

Arpan Das

dasarpan1@yahoo.co.in; arpand@barc.gov.in

1 Mechanical Metallurgy Division, Materials Group, Bhabha Atomic Research Centre (Department of Atomic Energy), Trombay, Mumbai, Maharashtra 400 085, India pressure vessel steels in the published domain [5-9]. The fracture properties of $20 \mathrm{MnMoNi} 55$ grade steel in a temperature regime of -50 to $-140{ }^{\circ} \mathrm{C}$ have been investigated elsewhere [8]. Microstructure and texture play crucial role in the mechanical responses of pressure vessel steels. It is demonstrated by Joo et al. [9] that the texture plays a major role in influencing the anisotropy of the Charpy energy of pipeline steel. Improvement in different physical and mechanical properties of these polycrystalline grain structures and hence increasing their performances by modifying and controlling their microstructure/texture has been of considerable interest in recent years [9-12]. Reactor pressure vessels are used in thick sections, which, when quenched, experience varying cooling rates along the thickness sections. This results in a non-uniform microstructure development, hence variation in mechanical responses. Thus, precise characterization of microstructure of these multi-phase steels at different cooling rates is important to tailor the microstructure for specific applications [13-16]. Currently the distinction and quantification of these multiple phases are still a big issue [10]. There is limited information available on the microstructural variations during different heat treatments of pressure vessel steels.

This study quantitatively analyzes the microstructure (i.e., phases, grain boundary rearrangements, grain sizes/types, and misorientation) of $20 \mathrm{MnMoNi} 55$ steel at different cooling rates. 


\section{Experiments and Analysis}

\section{Alloy and Properties}

The alloy used in this current study is a low-alloy steel designated as 20MnMoNi55 (German grade reactor pressure vessel steel). Nominal alloying composition of this steel (wt.\%) is: C 0.20, Mn 1.38, Si 0.24, S 0.005, P 0.011, Al 0.068, Mo 0.30, $\mathrm{Cr} 0.06$, Ni 0.52, Nb 0.032, and balance Fe. The steel was received as rectangular blocks in quenched-tempered conditions, which is a tempered bainite microstructure (AR - initial as received microstructure). Mechanical properties of the material have been experimentally investigated to be: yield strength (YS) $-455 \mathrm{MPa}$, tensile strength (UTS) - $620 \mathrm{MPa}$, and total elongation (EL) - 20.7\% under room temperature and strain rate $4 \times 10^{-3} \mathrm{~s}^{-1}$ [17]. The hardness of the alloy was found to be $\sim 200 \pm 5 \mathrm{Hv}$ [17].

\section{Dilatometry}

Cylindrical hollow samples with $5 \mathrm{~mm}$ outer diameter, $10 \mathrm{~mm}$ length, and $2 \mathrm{~mm}$ sheet thickness were used for dilatometry studies in a high-resolution dilatometer. Different samples were heated by induction at heating rate $5^{\circ} \mathrm{C} / \mathrm{s}$ to temperature of $1000{ }^{\circ} \mathrm{C}$ (in austenitizing regime) in vacuum of $5 \times 10^{-4} \mathrm{mbar}$, held for $15 \mathrm{~min}$, thus cooled (in $\mathrm{Ar}$ atmosphere) to room temperature (RT) at different cooling rates, $0.15-200{ }^{\circ} \mathrm{C} / \mathrm{s}$. The length change is recorded by a linear variable displacement transducer (LVDT) measuring head with a theoretical resolution of $0.05 \mu \mathrm{m}$. The $A c_{1}, A c_{3}$, $M_{s}, B_{s}$ temperatures were determined by principal of tangent method [18].

\section{Metallography}

All dilatometry tested samples were cut along the sample's length dimensions (rolling) and conventionally polished maintaining standard metallographic techniques and subsequently etched with $2 \%$ nital solution to reveal the final microstructures using optical microscopy.

\section{Electron Backscatter Diffraction}

Selected samples (i.e., $2,15,20$, and $200^{\circ} \mathrm{C} / \mathrm{s}$ ) were prepared for observation using scanning electron microscope-electron backscatter diffraction (SEM-EBSD) equipped with orientation imaging microscopy (OIM) software. Electro-polishing was performed (after conventionally polished) using electrolyte of mixture $\mathrm{HClO}_{4}: \mathrm{CH}_{3} \mathrm{COOH}=1: 9$ at $-15^{\circ} \mathrm{C}$ with voltage $20 \mathrm{~V}$ (DC). SEM-EBSD/OIM observations were conducted at an operating voltage $25 \mathrm{kV}$, working distance
$30 \mathrm{~mm}$, and tilt angle $70^{\circ}$. The step size of all scans was 0.10 $\mu \mathrm{m}$. EBSD scans were performed at the center of samples and included a significant number of representative grains.

The size, morphology, type, and misorientation $(\theta)$ of the $b c c$ grains were measured for all samples. Special grain boundaries (GBs), coincidence site lattice (CSL) boundaries [19] with $1 \leq \Sigma \leq 29$ were identified, and Brandon's criterion $\Delta \theta=15 / \Sigma^{0.5}$ [20] was used to categorize them. Microstructural parameters such as grain size, $\theta$, and grain boundary character distribution (GBCD): low angle grain boundaries (LAGB), high angle grain boundaries (HAGB), and coherent site lattice boundaries (CSLB) were evaluated. In present context, LAGB is defined as GB with $\theta=2^{\circ}-15^{\circ}$ and HAGB with $\theta>15^{\circ}$. By further processing of SEM-EBSD/OIM raw data, Kernel Average Misorientation (KAM) maps with their corresponding data were also extracted and interpreted with cooling rates and related phase mixtures.

\section{Results and Discussion}

\section{Continuous Cooling Transformation}

The starting condition is a tempered bainite microstructure and is the condition in which this steel is generally used in the nuclear reactor pressure vessels [4, 17]. Figure 1 presents the experimental dilatograms of 20MnMoNi55 steel for 12 different cooling rates on different samples: 0.15 , $0.30,1,2,5,15,20,40,80,120,160$, and $200{ }^{\circ} \mathrm{C} / \mathrm{s}$. The comparison of different transformation start temperatures with measured and calculated values [21,22] is summarized in Table 1. From these curves, transformation temperatures are determined by the method of tangents and confirmed by plotting the derivatives of curves. Transformation temperatures are plotted in continuous cooling transformation (CCT)

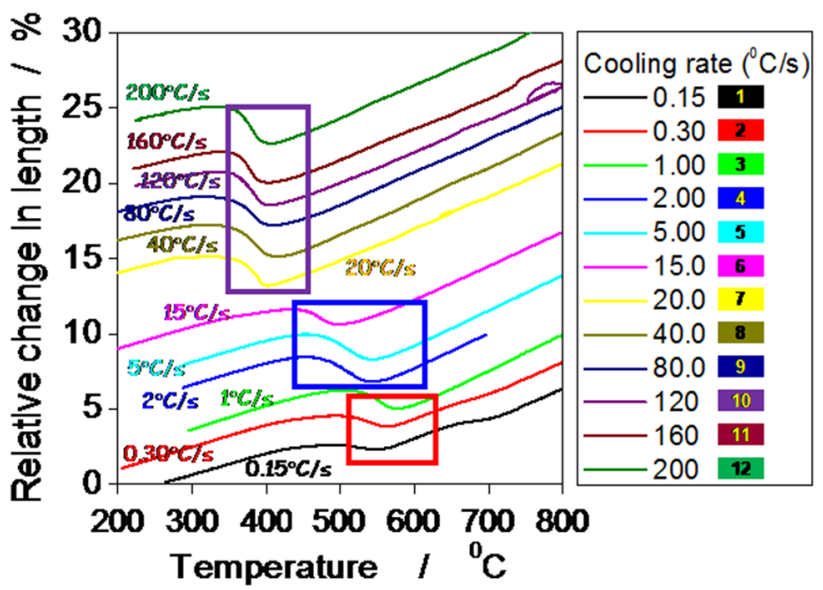

Fig. 1 Relative change in length versus temperature of 20MnMoNi55 steel cooled from $1000{ }^{\circ} \mathrm{C}$ in a dilatometer 
Table 1 Comparison of different phase transformation temperatures with measured and calculated values of 20MnMoNi55 steel [21, 22]

\begin{tabular}{llllllll}
\hline Ms [21] & Ms (measured) & Bs [21] & Bs (measured) & Ac1 [22] & Ac1 [measured] & Ac3 [22] & Ac3 (measured) \\
\hline $400.3^{\circ} \mathrm{C}$ & $405^{\circ} \mathrm{C}$ & $604{ }^{\circ} \mathrm{C}$ & $600{ }^{\circ} \mathrm{C}$ & $702.8^{\circ} \mathrm{C}$ & $715^{\circ} \mathrm{C}$ & $800.7^{\circ} \mathrm{C}$ & $790{ }^{\circ} \mathrm{C}$
\end{tabular}

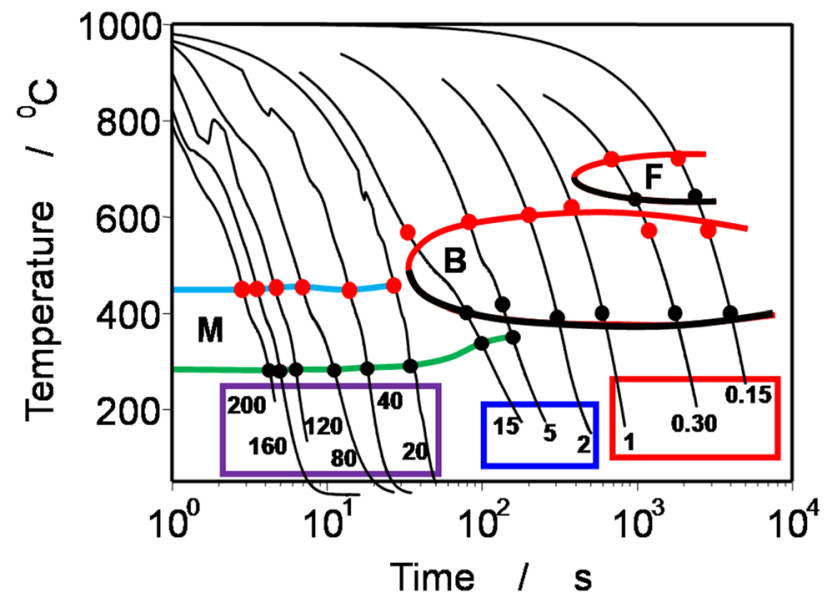

Fig. 2 Continuous cooling transformation (CCT) diagrams of 20MnMoNi55 steel

diagrams (see Fig. 2). The start and end of transformations are indicated by red and black dots/lines, respectively. At lower cooling rates of 0.15 and $0.3^{\circ} \mathrm{C} / \mathrm{s}$, two transformations appear to occur as seen by the bump in curve (red rectangle in Fig. 1).

There is formation of proeutectoid ferrite followed by bainitic phase in this cooling rate regime (i.e., 0.15 and $0.3{ }^{\circ} \mathrm{C} / \mathrm{s}$ ) (Figs. 3 and 4). With increasing cooling rate from 1 to $2{ }^{\circ} \mathrm{C} / \mathrm{s}$, only one transformation is seen, most likely to be bainite transformation. At $5-15^{\circ} \mathrm{C} / \mathrm{s}$, two transformations appear to be merged in one (see Fig. 1) and it is likely that before the bainite transformation completes, martensite starts to appear. At higher cooling rates $\left(>20{ }^{\circ} \mathrm{C} / \mathrm{s}\right)$, the transformation temperature is independent of cooling rate suggesting the transformation to be martensite. For comparison, the CCT diagram of a similar alloy SA 508 steel is shown in the literature [23, 24]. The transformations as marked on SA 508 steel CCT diagram [23] are similar to that formed experimentally in the present alloy.

\section{Microstructure}

\section{Phase Transformations}

As the mixture of phases generated in these steels can be difficult to identify through conventional optical microscopy because they are small and are of a similar kind (Fig. 3). SEM-EBSD/OIM experiments (Fig. 4) were performed to map the orientations of different phases revealing the morphologies and characteristics of the transformed products in 20MnMoNi55. Figure 4 presents the inverse pole figure (IPF) maps of selected samples. At slower cooling rates (i.e., $2^{\circ} \mathrm{C} / \mathrm{s}$ ), the prior austenite grain size (PAGS) was prominently seen within which packets of ferrite of similar orientations were observed (see Figs. 3 and 4). At cooling rates, $0.15-0.3 / \mathrm{s}$, proeutectoid ferrite (dispersed and blocky morphology) and bainite (coarse laths kind) are seen to be present. At cooling rates, $1-2{ }^{\circ} \mathrm{C} / \mathrm{s}$, apart from large packets of Widmanstätten ferrite (clustered sometimes), finer length scale features were seen (only bainite-coarse sheaves with differentially oriented) (Figs. 3 and 4). The microstructures become finer with the increase in cooling rate.

At cooling rate $5-15^{\circ} \mathrm{C} / \mathrm{s}$, bainite (coarse sheaves) and martensite (lath kind) are present. At higher cooling rates, 20-200 ${ }^{\circ} \mathrm{C} / \mathrm{s}$, finer length scale features were also present throughout the microstructure (Fig. 4). From the dilatometry curves, CCT diagram (see Figs. 1 and 2, respectively), optical, and electron micrographs (Figs. 3 and 4), the transformations of $20 \mathrm{MnMoNi} 55$ steel can be divided into four distinct regimes: $0.15-0.30,1-2,5-15$, and $20-200{ }^{\circ} \mathrm{C} / \mathrm{s}$. These findings are in conformity with Ref. [25]. Different ferrite-grain characteristics were observed depending upon cooling rates. The ferrite phase is normally composed of large and small equiaxed grains (distinct orientations). Different morphologies of Widmanstätten ferrite like Refs. [25, 26] were also observed. Widmanstätten ferrite is a ferritic structure that occurs by a shear transformation [25].

At high cooling rates (Fig. 4), the morphologies of bainite and martensite are almost similar kind [27], and thus it is not easy to differentiate between these two. After identifying the grains, different grain functions such as mean grain band contrast, mean band slope, grain internal mean misorientation, grain size and grain shape aspect ratio have been used by Zhu et al. [10] in their elegant study as criteria to separate phases according to the composition (ferrite/bainite/martensite) and morphology (granular or lamellar) of the microstructure. With increase in cooling rates $\left(20 \rightarrow 200^{\circ} \mathrm{C} / \mathrm{s}\right)$, the morphology of martensite laths changes randomly. It is well known that the formation of one martensite unit generally stimulates the nucleation of other martensite variants [28]. The aspect ratio of martensite increased with cooling rate (see Fig. 4), which may be due to this variant nature of martensites [29-31]. It is clear that the growth of martensitic plate is usually locked by austenite GB [31, 32] or the martensite plate formed previously, and hence, meaning of 

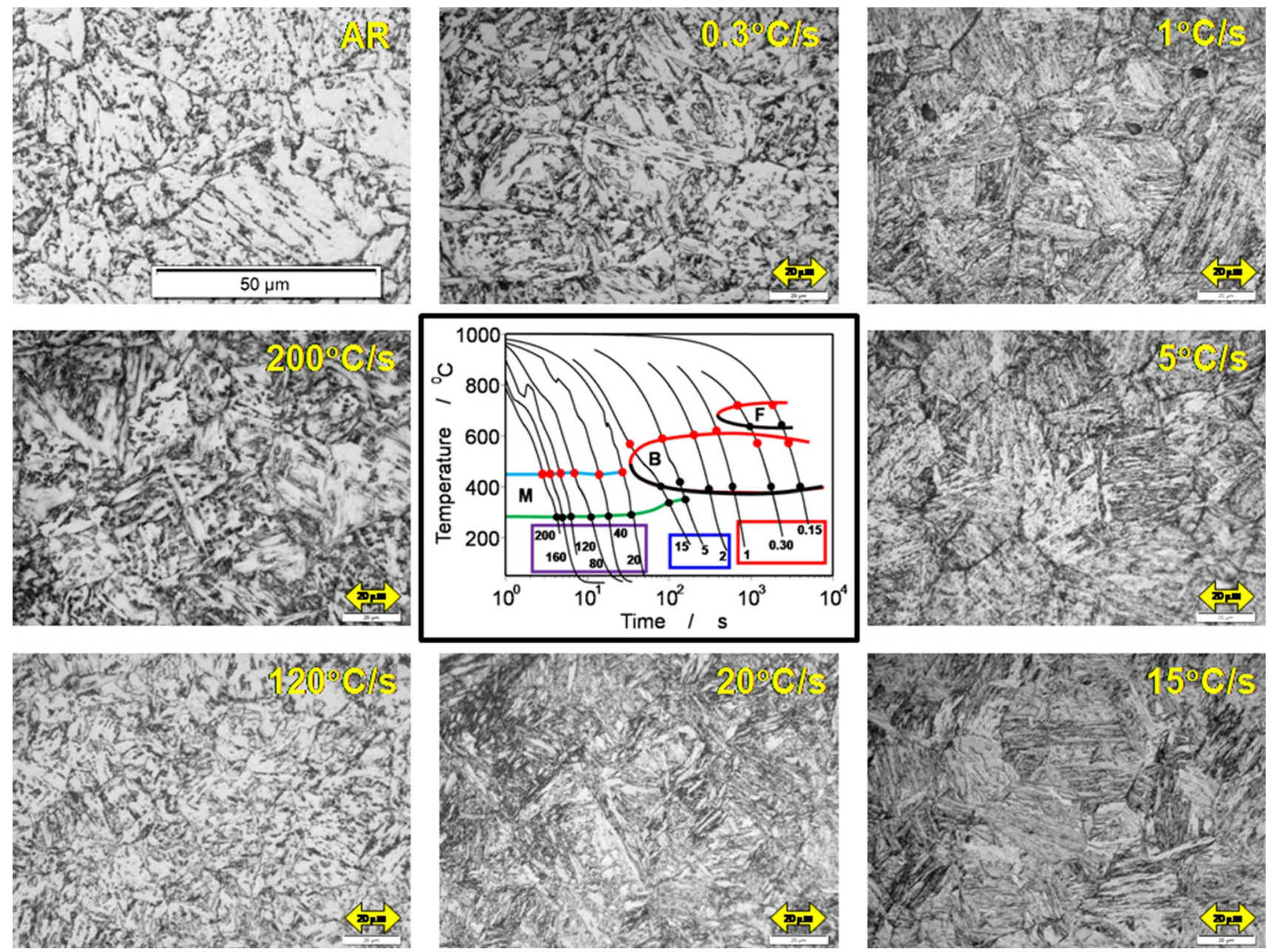

Fig. 3 Optical micrographs of $20 \mathrm{MnMoNi} 55$ steel in AR condition and at selected cooling rates: $0.3,1,5,15,20,120$, and $200{ }^{\circ} \mathrm{C} / \mathrm{s}$. All micrographs (except AR) are in same magnification

martensite-aspect ratio becomes very complicated [32]. The width of bainitic laths reduced with increase in cooling rates (Fig. 4). The present investigations match with Lan et al.'s [33] findings for low carbon steel.

In summary, with increasing cooling rate, the microstructure changed from granular bainite to a mixture of bainitic ferrite plus granular bainite (at $0.15-0.3{ }^{\circ} \mathrm{C} / \mathrm{s}$ ), to complete bainite (at $1-2{ }^{\circ} \mathrm{C} / \mathrm{s}$ ), bainite and martensite (at $5-15{ }^{\circ} \mathrm{C} / \mathrm{s}$ ), and complete martensite (at $20-200{ }^{\circ} \mathrm{C} / \mathrm{s}$ ) with the decrease in cooling time. To ensure the integrity of heavy section components, it should be proved that the material maintains not only high strength, ductility, and fracture toughness but also good homogeneity of mechanical properties, as per Druce et al. [34]. Hence, the homogeneity of mechanical properties can only be achieved by maintaining the homogeneity of microstructures of the thick sections by designing proper heat treatment cycles and proper steel design criterion.

\section{Grain Boundary Spacing}

The distribution of GB-spacing is an important feature of the microstructure that determines the strength and toughness of the material. Figure 5 shows the HAGB and LAGB distributions on image quality (IQ) maps for selected cooling rates. At low cooling rates (Fig. 5c), the boundary spacing between HAGBs is large and LAGBs are seen within the grains. However, at higher cooling rates (Fig. 5d, e), the spacing between HAGBs (blue lines) has reduced significantly. The spatial distribution of GBs with misorientations $\left(\theta>2^{\circ}\right)$ is shown in Fig. 5. The plots of cumulative $b c c$-grain size distribution $\left(\theta>2^{\circ}\right)$ as a function of cooling rates-are presented in Fig. 6. It is observed that the nature of distribution of $b c c$ - grain size $\left(\theta>2^{\circ}\right)$-is similar for all cooling rates as per the raw EBSD data.

The median values (at cumulative probability of 0.5 ) were $20 \mu \mathrm{m}$ for $2{ }^{\circ} \mathrm{C} / \mathrm{s}, 8 \mu \mathrm{m}$ for $15^{\circ} \mathrm{C} / \mathrm{s}, 5 \mu \mathrm{m}$ for $20^{\circ} \mathrm{C} / \mathrm{s}$, 


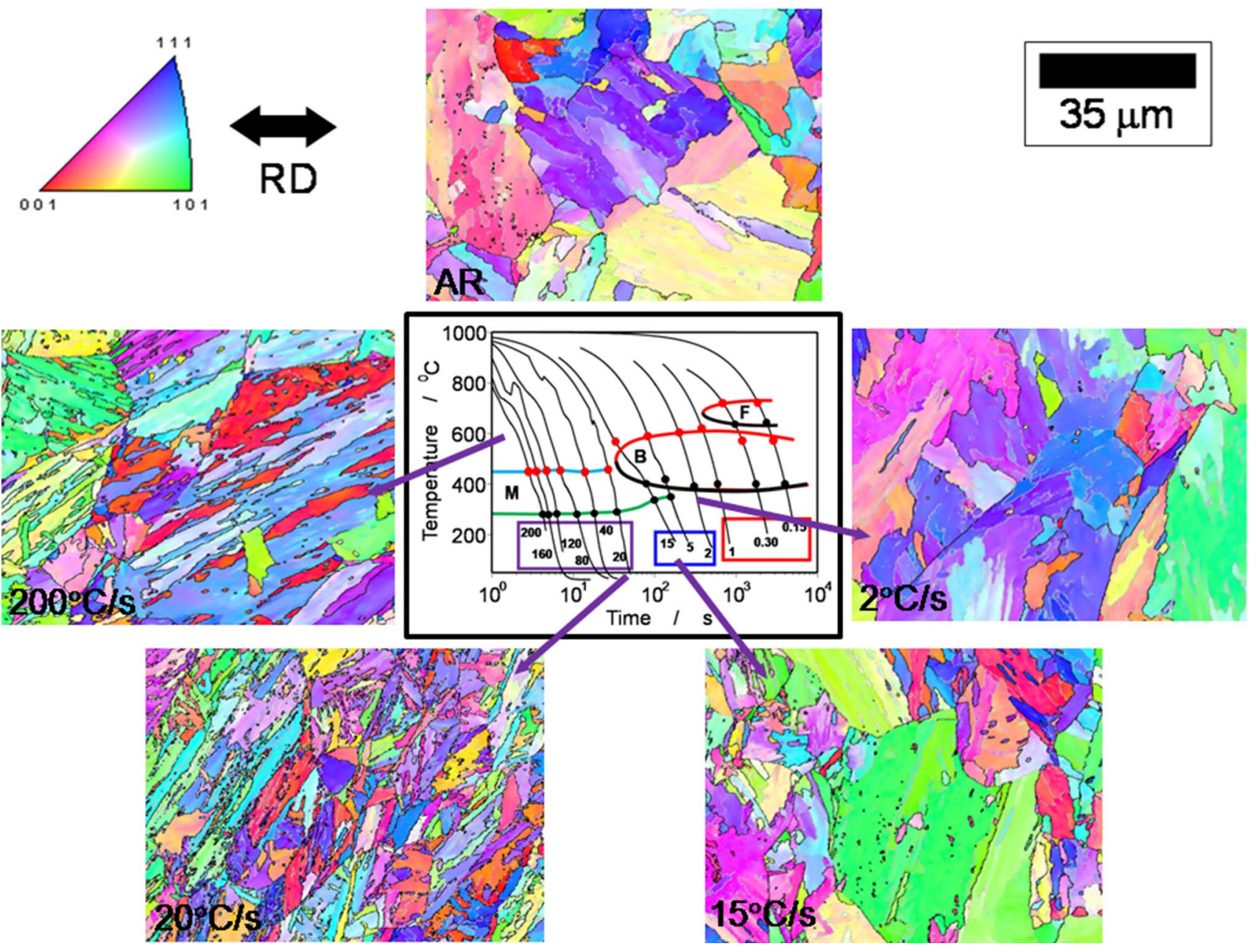

Fig. 4 SEM-EBSD/OIM IPF micrographs of 20MnMoNi55 steel in AR condition and at selected cooling rates: 2, 15, 20, and 200 ${ }^{\circ} \mathrm{C} / \mathrm{s}$. All IPFs are in same magnification

and $6.5 \mu \mathrm{m}$ for $200{ }^{\circ} \mathrm{C} / \mathrm{s}$. Grain size differences between 20 and $200{ }^{\circ} \mathrm{C} / \mathrm{s}$ samples are mainly attributed to the scatter in the data due to limited number of EBSD experiments. The distribution of only HAGBs is not shown due to lack of statistics. The general trend is that with increasing cooling rate, the distribution shifts toward smaller grain sizes.

The spatial aspect of $b c c$ - grain distribution through cooling rate variation-depends on growth of the respective plates/sheaves, which causes austenite grain partitioning [31]. Hence, there is variation in accommodation of transformation strains in the microstructures. The spatial aspect of $b c c$-grains $\left(\theta>2^{\circ}\right)$-designate the size, geometry, number, density, and distribution of respective phases' units that make-up the total volume fraction modified/transformed through different cooling treatments. The size of $b c c$ units is gauged by transfer of transformation strains to austenite [31, 35].

\section{Grain Boundary Character Distribution}

GBC defines the type of boundary, in terms of its misorientation, such as low angle and high angle, or in terms of its CSL structures. As per Kim et al. [36], GBCD is a sensitive metric of any polycrystalline microstructure that can be closely related to the macroscopic properties. Figure 7 illustrates the variation of LAGB and HAGB fractions with cooling rates. It is manifested that with increasing cooling rate, the area fraction of HAGBs rises and that of LAGBs decreases. The prominent CSLBs (e.g., $\Sigma 3, \Sigma 13 \mathrm{~b}$, and $\Sigma 33 \mathrm{c}$ ) are also observed in $20 \mathrm{MnMoNi} 55$ steel after cooling at different rates. Their fractions as a function of cooling rates are also presented in Fig. 8.

The alteration in transformation route by the change in cooling rate of these steels affects the extent of twin boundaries (TBs) and their coherency. $\Sigma 3$ was found to be the 
Fig. 5 SEM-EBSD/OIM image quality micrographs showing LAGB and HAGBs of 20MnMoNi55 steel at selected cooling rates: (a) 2, (b) 15, (c) 20 , and (d) $200{ }^{\circ} \mathrm{C} / \mathrm{s}$
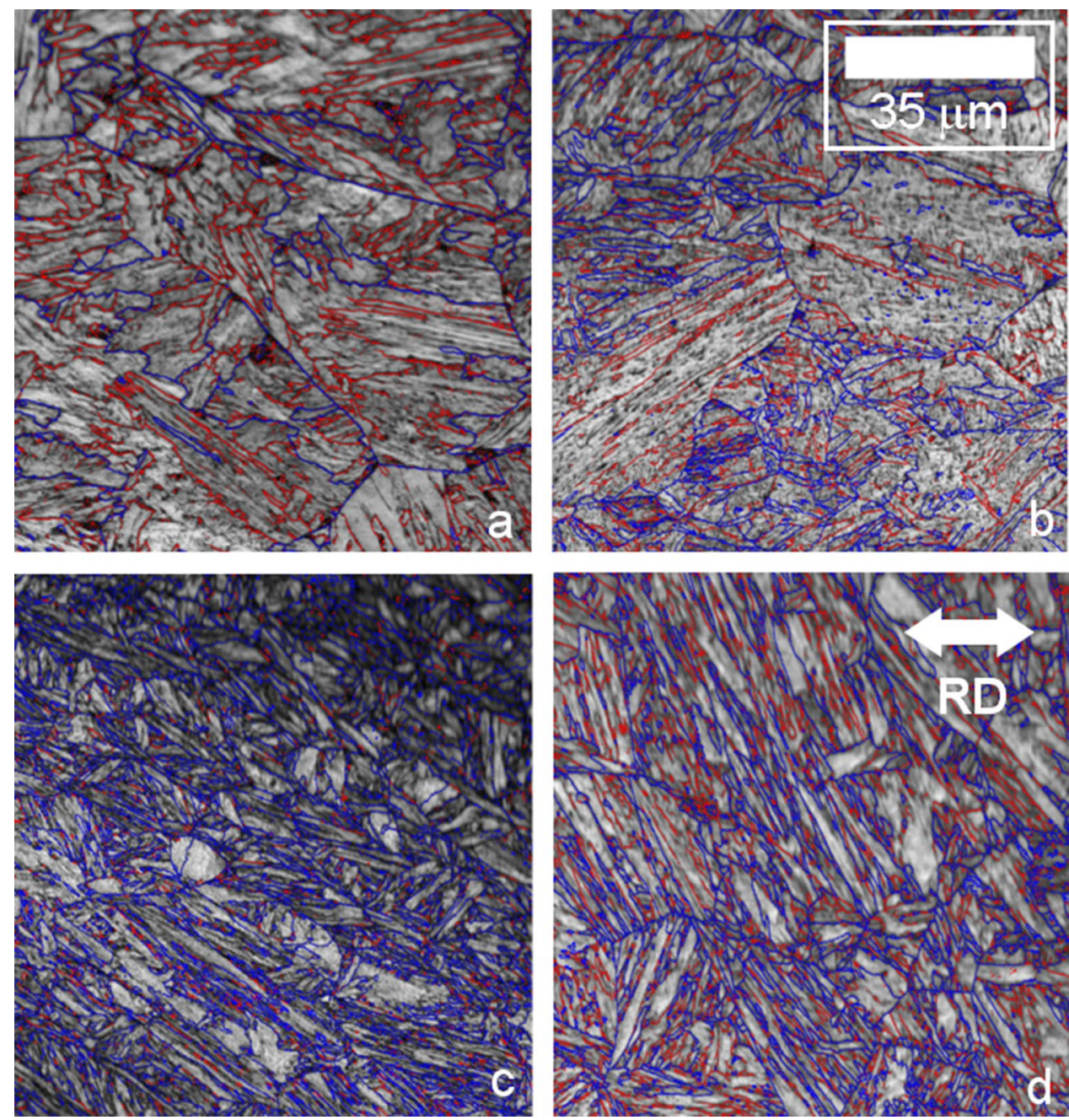

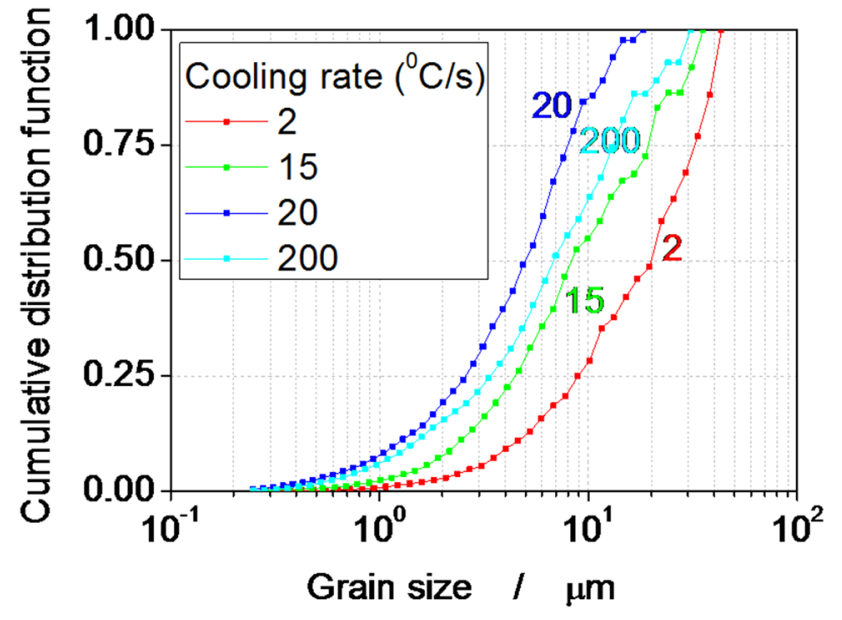

Fig. 6 Cumulative grain size distribution of 20MnMoNi55 steel for various cooling rates $\left({ }^{\circ} \mathrm{C} / \mathrm{s}\right)$ as shown in legend

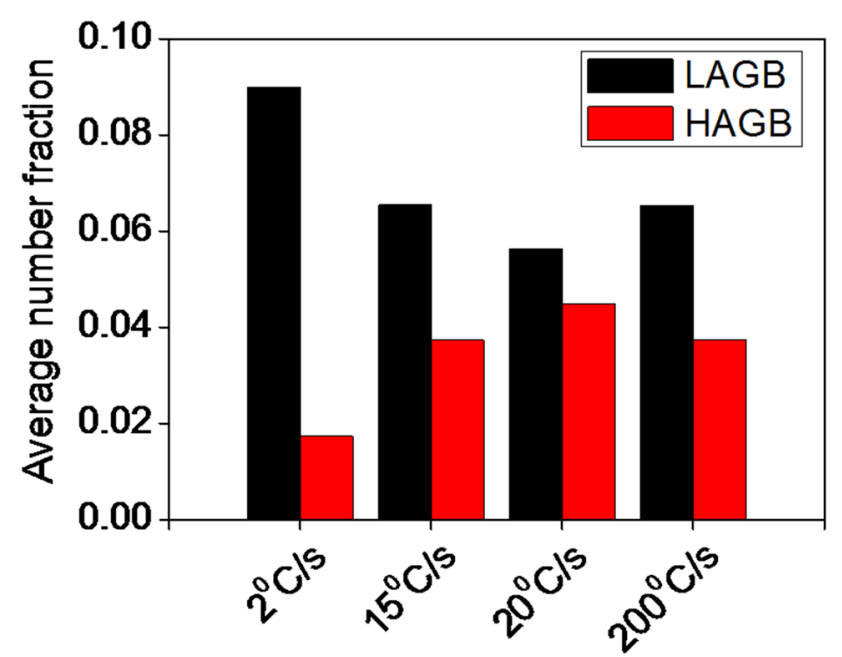

Fig. 7 Average number fraction of LAGBs and HAGBs as a function of cooling rates of $20 \mathrm{MnMoNi} 55$ steel 


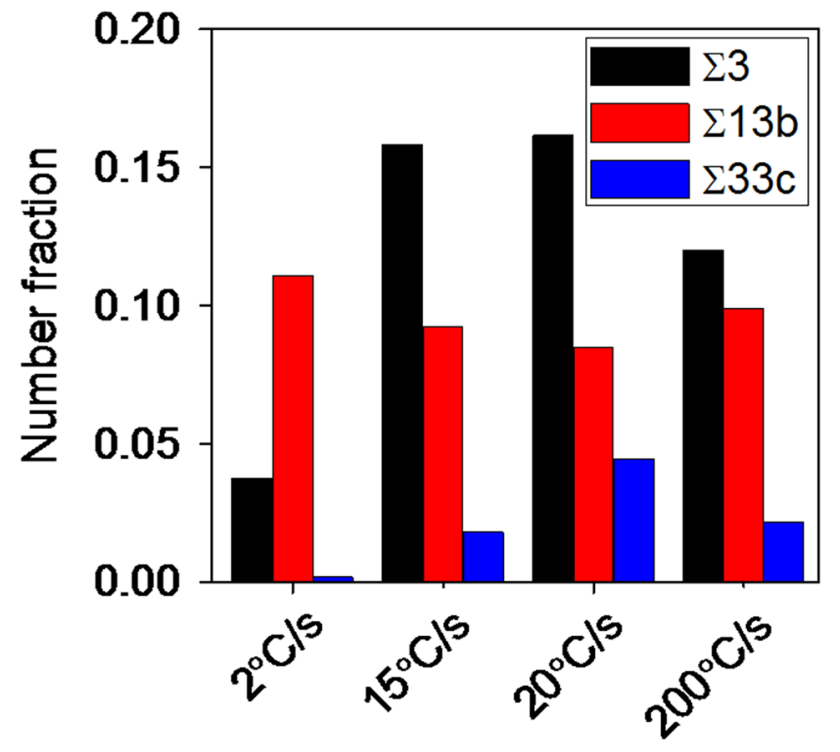

Fig. 8 Variation of $\Sigma 3, \Sigma 13 b$, and $\Sigma 33$ c boundaries as a function of cooling rates of $20 \mathrm{MnMoNi} 55$ steel

most frequently observed boundaries compared to other $\Sigma$ boundaries for all cooling rates.

At higher cooling rates (e.g., 15, 20, and $200{ }^{\circ} \mathrm{C} / \mathrm{s}$ ), significant number of $\Sigma 3$ boundaries were created, most likely due to the presence of martensite laths. $\Sigma 13$ b and $\Sigma 33$ c boundaries were also observed, although not as prominently as $\Sigma 3$ boundaries. $\Sigma 33$ c boundaries too were found (less amount) at higher cooling rates (e.g., 20 and $200^{\circ} \mathrm{C} / \mathrm{s}$ ) suggesting that these represent martensite lath boundaries. For $2{ }^{\circ} \mathrm{C} / \mathrm{s}$-specimens, $\Sigma 33 \mathrm{c}$ boundaries are found to be a negligible quantity. $\Sigma 13 \mathrm{~b}$ was found to be the maximum for 2 and $200{ }^{\circ} \mathrm{C} / \mathrm{s}$-specimens. According to Watanabe et al. [37], the thermal stability of GB microstructure of a polycrystal may be controlled by the fraction of low-energy boundaries with higher thermal stabilities, i.e., GBCD.

As per the hypothesis that the GB density is inversely correlated to the boundary energy [38], $\Sigma 3$ is the highly populated boundary in both $b c c$ and $f c c$ polycrystalline materials. Both high-energy and low-energy GBs (on availability) often serve to decrease the relative population of coherent twins in the $b c c$ metals (as for $2{ }^{\circ} \mathrm{C} / \mathrm{s}$ sample). New grains, which are twin related w.r.t. subsequent growing grains, sometimes form during the migration of HAGBs [39]. Offerman et al. [40] researched on the grain nucleationgrowth micro-mechanisms during phase transformations of $0.21 \mathrm{C}-0.51 \mathrm{Mn}-0.20 \mathrm{Si}$ steel. According to them, these mechanisms during phase transformations will contribute to the development of optimal mechanical properties of steels.

As per Zhao et al. [41], GB has higher energy, which is easy to meet the condition of energy fluctuation for phase transformation. LAGB morphologies are seen to be very fine (few micrometers of width) (Fig. 5). Lower angle misorientations between the neighboring plates are connected with nucleation of the secondary plates (see Fig. 5). The sub-grains gradually turn into crystallites separated by relatively LAGBs. LAGB and HAGBs are found to be clustered in almost all grains observed for all cooling rates (Fig. 5). This usually ends up in the formation of a complex network of LAGBs and HAGBs. LAGBs are also found finely distributed throughout the microstructures. Grossly, it can be remarked that with increase in cooling rate, LAGB fraction decreased and HAGB fraction increased (Fig. 7). This may be attributed to the generation of transformation strains due to formation of lower bainite and martensite at higher cooling rates, which will be discussed in more detail later.

It was found that the preferential distribution for ferrite LAGBs was random (Fig. 5). Furthermore, with increasing cooling rate, different phases became increasingly subdivided into hierarchical fragments delineated by HAGBs and filled with sub-grains separated by LAGBs. Several grains, predominantly surrounded by HAGBs, were intermittently observed at cooling rate $2{ }^{\circ} \mathrm{C} / \mathrm{s}$, and their size increased (up to $10 \mu \mathrm{m}$ ) with cooling rate. The bainitic-ferrite width and aspect seem to be related to cooling rate. According to Wang et al. [32], the large variation in aspect ratio associated with bainite plates implies that the interface between plate/matrix should one be of low shear deformation.

Sub-grains formation at different cooling rates is attributed to the phase transformation and/or the evolution of complex phase mixture. The (sub) grains were partially surrounded by HAGBs which were normally not formed and, rather, regular sub-grains endured up to the largest cooling rate used, albeit their grain misorientations eventually rose with the transformation strain (at higher cooling rates [42]. With alteration of transformation strains (due to phase transformation), ferrite phase regions covered with sub-grains became progressively subdivided into coarse/rough fragments separated by the HAGBs at higher cooling rates. Moreover, new grains (new phases), increasingly encompassed by HAGBs, emerged with increasing cooling rate within the sub-grain matrix. It was understood that these grains often nucleated from large misoriented sub-grains, mainly located along interphase boundaries, and eventually grew through the migration of respective LAGBs. Different CSLBs are also observed and measured for all samples (Fig. 8). It is apparent that the rise of $\Sigma 3$ TBs is primarily responsible for the increase in total number of CSLB, as for other materials with lower SFE [43, 44]. The improvement in material properties is generally attributed to the increase in proportion of low $\Sigma$ CSL Spe$\operatorname{cial}(S)$ boundaries as per Randle [45]. 

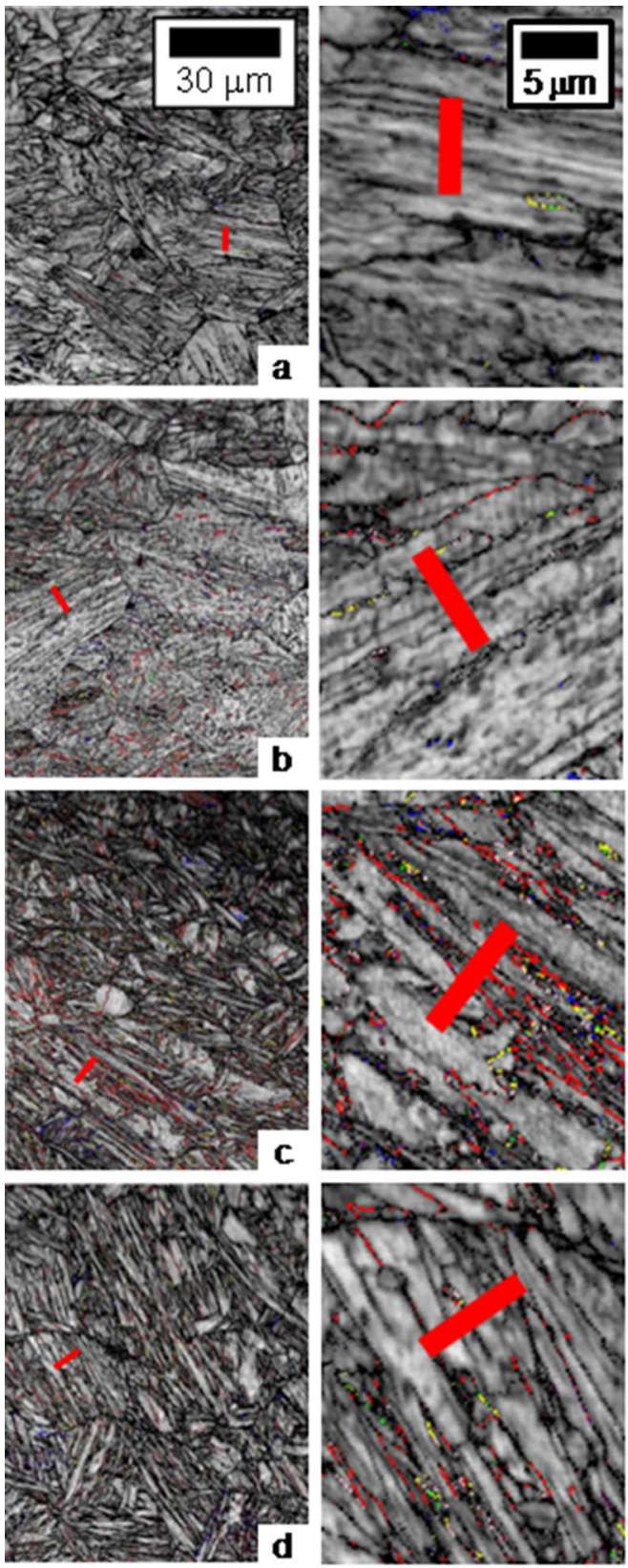

Fig. 9 The conventional image quality (IQ) maps (intragranular misorientation) shown on the left column. The red line on each map corresponds to the line scan of the misorientations both point-to-point results of which are shown on the right column. The boundaries

\section{Grain Boundary Misorientations}

IQ map (left column) and misorientations (KAM/point-topoint) at selected cooling rates are presented in Fig. 9. KAM is a measure of local misorientation within a grain, and a high value of KAM corresponds to high degree of crystal defects within grains $[45,46]$. The higher cooling rates of 20 and $200{ }^{\circ} \mathrm{C} / \mathrm{s}$ show higher KAM values as expected.

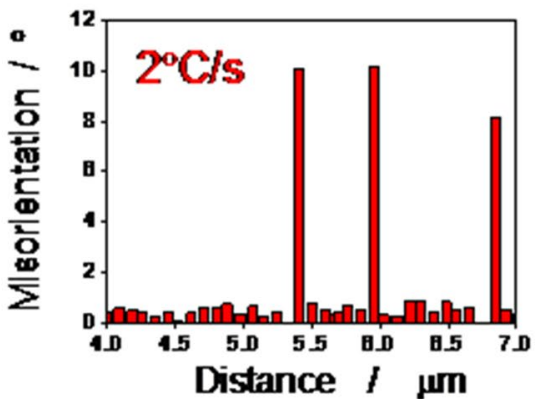

\section{Bainite}

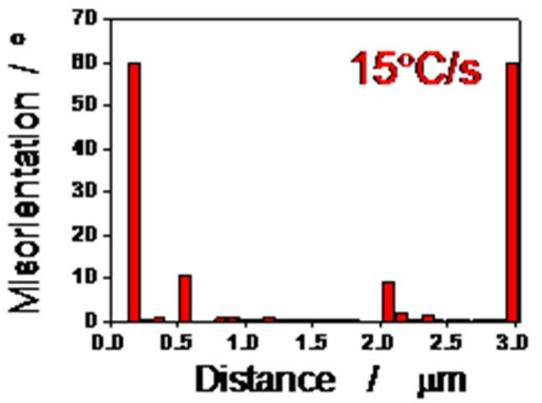

\section{Bainibe +} Martensinte

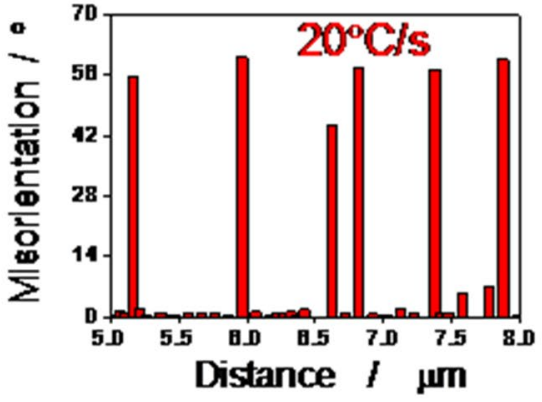

Martensite

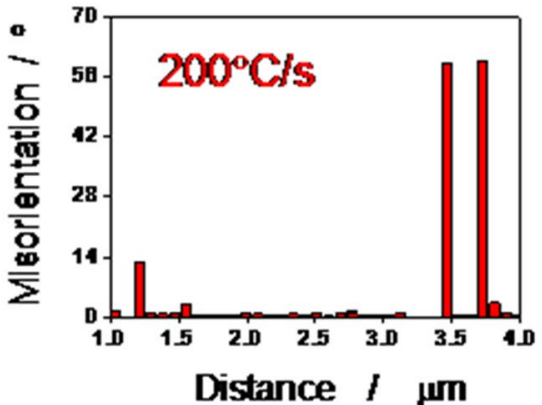

Marbensibe

marked red are $\Sigma 3$ and those marked other colors are other $\Sigma$ boundaries. The cooling rates are mentioned in the plots and the estimates of the phases present written on the right

Examining the large lattice curvature and the presence of sub-boundaries in bainitic grains, Zaefferer et al. [47] used KAM to identify these grains in steels. The intragranular grain misorientations of selected samples are shown in Fig. 9. At low cooling rate (i.e., $2{ }^{\circ} \mathrm{C} / \mathrm{s}$ ), the misorientation across boundaries does not exceed $12^{\circ}$, suggest the absence of twins/martensite. At $15^{\circ} \mathrm{C} / \mathrm{s}$ and higher, the misorientation across boundaries $60^{\circ}$ suggest the formation of 
martensite. According to Zhu et al. [10], large packets of slightly misoriented laths $\left(\theta<20^{\circ}\right)$ correspond to lath bainite structure.

This is in agreement with the present study (Figs. 5 and 6) for cooling rate $15{ }^{\circ} \mathrm{C} / \mathrm{s}$. It is worth stating that almost all the grains (equiaxed ferrite/granular bainite) are surrounded by grain boundaries with misorientation between $20^{\circ}$ and $48^{\circ}$ [10]. The coalesced bainite has large misorientations $\left(\theta=50^{\circ}-60^{\circ}\right)$ with surrounding features for $15^{\circ} \mathrm{C} / \mathrm{s}$ sample. These findings are also in agreement with the study of Keehan et al. [48]. Figure 10 shows total misorientation distribution profiles for angles $(\theta)$ between $0^{\circ}$ and $60^{\circ}$ determined by FEG-EBSD/OIM analysis. There is significant variation in distribution of GB misorientations with cooling rate, due to alteration of phase transformation products (see Figs. 9 and 10). Three prominent peaks were observed for all samples (e.g., $3^{\circ}, 30^{\circ}$ and $60^{\circ}$ ). The peak at low angles indicates excess of LAGBs. Two additional peaks (weak) were also noticed at misorientation angles of $45^{\circ}$ and $55^{\circ}$.

According to Zhu et al. [10], upper bainite displays few HAGBs $\left(\theta>50^{\circ}\right)$ but a greater number of LAGBs, whereas lower bainite displays a high proportion of boundaries (with $\left.\theta=50^{\circ}-60^{\circ}\right)$ and very few GBs with low misorientations $\left(\theta<20^{\circ}\right)$. The lower bainite phase is generally separated by small angle misorientations $\left(\theta=2^{\circ}-8^{\circ}\right)$, whereas the packet boundaries have large misorientations $\left(\theta=50^{\circ}-60^{\circ}\right)$, which is as per Keehan et al. [48]. It can be seen from Fig. 10 that the peak size and shape (profile geometry) change with cooling rate, due to the alteration of phase mixtures. Maximum to minimum GB misorientation fraction (at $3^{\circ}$ ) was found in the order: $2{ }^{\circ} \mathrm{C} / \mathrm{s}>200{ }^{\circ} \mathrm{C} / \mathrm{s}>20{ }^{\circ} \mathrm{C} / \mathrm{s}>15^{\circ} \mathrm{C} / \mathrm{s}$. Interactions and tangling of high densities of dislocations (at martensite laths) can produce local misorientations with HAGB, and, thereby, a sufficient grain refinement (Figs. 4 and 5). Lath bainite structure is comprised of packets of fine laths with

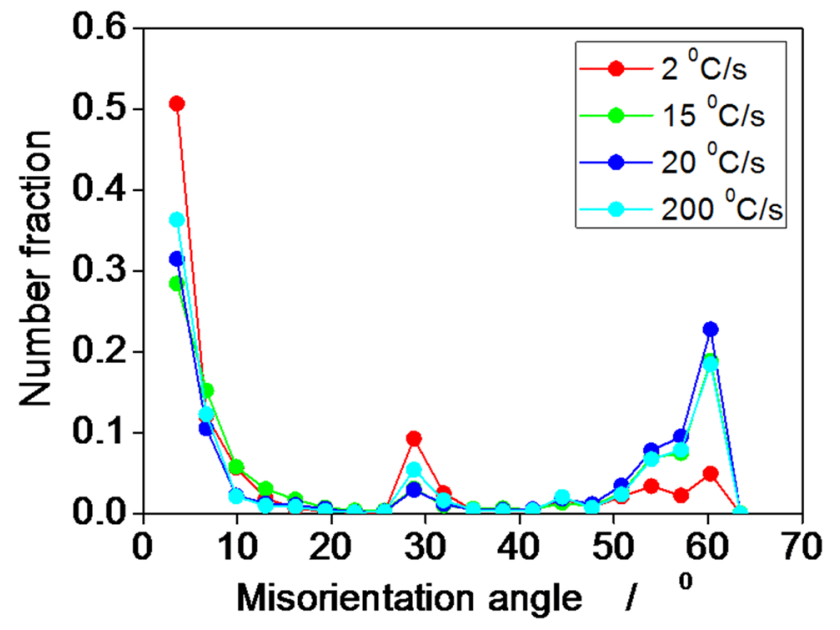

Fig. 10 Misorientation angle distribution at different cooling rates a width in the range $0.20-1.0 \mu \mathrm{m}$ at cooling rate $15^{\circ} \mathrm{C} / \mathrm{s}$ (Figs. 4 and 5). At cooling rate $200{ }^{\circ} \mathrm{C} / \mathrm{s}$, many block and packet boundaries are also observed (Figs. 5 and $9 \mathrm{~d}$ ).

The cooling rate of $2{ }^{\circ} \mathrm{C} / \mathrm{s}$ was found to have the most prominent $30^{\circ}$ misorientation peak (highest fraction) (see Fig. 10). Their order (highest to lowest number fraction) has been found to be: $2{ }^{\circ} \mathrm{C} / \mathrm{s}>200{ }^{\circ} \mathrm{C} / \mathrm{s}>15{ }^{\circ} \mathrm{C} / \mathrm{s}>20{ }^{\circ} \mathrm{C} / \mathrm{s}$ for $30^{\circ}$ misorientation. The maximum to minimum number fraction of boundaries with $60^{\circ}$ misorientation was in the order of: $20^{\circ} \mathrm{C} / \mathrm{s}>15^{\circ} \mathrm{C} / \mathrm{s}>200{ }^{\circ} \mathrm{C} / \mathrm{s}>20^{\circ} \mathrm{C} / \mathrm{s}$. The alteration of GB fraction with $\theta=60^{\circ}$ as a function of cooling rate is due to gathering of lattice dislocations and release of secondary dislocations by a GB through phase transformations [49, 50]. This may be attributed to the strains (i.e., transformation strains) generated in different phases due to phase transformation $[49,50]$ at different cooling rates. Misorientation of $60^{\circ}$ may include $\Sigma 3$ TBs as the alloy is $\langle 110\rangle$ (bcc texture) preferentially. However, as TBs normally display low diffusivity, $2{ }^{\circ} \mathrm{C} / \mathrm{s}$-sample exhibits less number of $\Sigma 3$ boundaries compared to the rest. For large grain misorientations, GBs start to lose anisotropic properties usually ascribed to the dislocation networks seen in LAGBs [51]. Misorientations between neighboring martensite laths correspond to different variants. These laths are normally separated by HAGB with $\theta>15^{\circ}$, while between the laths $\theta$ is smaller and is in agreement with the literature [52]. Martensitic transformations are known to result in geometrically necessary dislocations (GND) [52]. The high toughness and strength of this lath martensite are mainly attributed to HAGB between the blocks and packets which hinder dislocation movements [52]. The sub-block types of martensite boundary at $200{ }^{\circ} \mathrm{C} / \mathrm{s}$ are separated by LAGBs. However, the specific misorientation angles of $45^{\circ}, 53^{\circ}$ (Fig. 10) could not be uniquely associated with specific block or packet boundaries.

\section{Conclusions}

The effect of cooling rate on different phase transformations characteristics, microstructural variations, and GB evolution has been investigated on $20 \mathrm{MnMoNi} 55$ steel. From the current experimental observations, the following conclusions are drawn:

(a) Continuous cooling from 0.15 to $0.3{ }^{\circ} \mathrm{C} / \mathrm{s}$ revealed two transformations products: proeutectoid ferrite and bainite. Complete bainite phase is seen from $1-2{ }^{\circ} \mathrm{C} / \mathrm{s}$. Both bainite and martensite transformations occurred in the cooling rate regime of $5-15{ }^{\circ} \mathrm{C} / \mathrm{s}$. Complete martensitic transformation was observed at cooling rate $20{ }^{\circ} \mathrm{C} / \mathrm{s}$ and above.

(b) At higher cooling rates, the grain size distribution shifted to lower values. The median values (of grain 
size) were found to be: $20 \mu \mathrm{m}$ for $2{ }^{\circ} \mathrm{C} / \mathrm{s}, 8 \mu \mathrm{m}$ for $15^{\circ} \mathrm{C} / \mathrm{s}, 5 \mu \mathrm{m}$ for $20^{\circ} \mathrm{C} / \mathrm{s}$, and $6.5 \mu \mathrm{m}$ for $200{ }^{\circ} \mathrm{C} / \mathrm{s}$.

(c) Maximum to minimum grain boundary misorientation fractions (for $3^{\circ}, 30^{\circ}$ and $60^{\circ}$ ) were in the order of: [2 $\left.{ }^{\circ} \mathrm{C} / \mathrm{s}>200{ }^{\circ} \mathrm{C} / \mathrm{s}>20^{\circ} \mathrm{C} / \mathrm{s}>15^{\circ} \mathrm{C} / \mathrm{s}\right],\left[2{ }^{\circ} \mathrm{C} / \mathrm{s}>200{ }^{\circ} \mathrm{C} /\right.$ $\left.\mathrm{s}>15^{\circ} \mathrm{C} / \mathrm{s}>20^{\circ} \mathrm{C} / \mathrm{s}\right]$, and $\left[20^{\circ} \mathrm{C} / \mathrm{s}>15^{\circ} \mathrm{C} / \mathrm{s}>200^{\circ} \mathrm{C}\right.$ $/ \mathrm{s}>20^{\circ} \mathrm{C} / \mathrm{s}$ ], respectively. This was attributed to variation in complex phase mixtures as a function of cooling rates.

(d) With the increase in cooling rate, LAGB decreased and HAGB increased. CSL grain boundaries were strongly dependent upon the cooling rates. $\Sigma 3$ boundaries were found to be prominent for 15,20 , and $200{ }^{\circ} \mathrm{C} / \mathrm{s}$ samples.

Disclosures No potential conflict of interest was reported by the authors.

\section{References}

1. R.O. Ritchie, W.L. Server, R.A. Wullaert, Critical fracture stress and fracture strain models for the prediction of lower and upper shelf toughness in nuclear pressure vessel steels. Metall. Trans. A 10(10), 1557-1570 (1979)

2. G.R. Odette, G.E. Lucas, Recent progress in understanding reactor pressure vessel steel embrittlement. Radiat. Eff. Defects Solids 144(1-4), 189-231 (1998)

3. T.S. Byun, J.H. Hong, F.M. Haggag, K. Farrell, E.H. Lee, Measurement of through-the-thickness variations of mechanical properties in SA508 Gr. 3 pressure vessel steels using ball indentation test technique. Int. J. Press. Vessels Pip. 74(3), 231-238 (1997)

4. K.D. Haverkamp, K. Forch, K.H. Piehl, W. Witte, Effect of heat treatment and precipitation state on toughness of heavy section $\mathrm{Mn}-\mathrm{Mo}-\mathrm{Ni}$-steel for nuclear power plants components. Nucl. Eng. Des. 81(2), 207-217 (1984)

5. H. Pous-Romero, H.K.D.H. Bhadeshia, Continuous cooling transformations in nuclear pressure vessel steels. Metall. Mater. Trans. A 45(11), 4897-4906 (2014)

6. P. Bowen, C.A. Hippsley, J.F. Knott, Effects of segregation on brittle fracture and fatigue crack growth in coarse-grained, martensitic A533B pressure vessel steel. Acta Metall. 32(5), 637-647 (1984)

7. A. Pineau, Development of the local approach to fracture over the past 25 years: theory and applications. Int. J. Fract. 138(14), 139-166 (2006)

8. A. Gopalan, M.K. Samal, J.K. Chakravartty, Fracture toughness evaluation of $20 \mathrm{MnMoNi} 55$ pressure vessel steel in the ductile to brittle transition regime: experiment \& numerical simulations. J. Nucl. Mater. 465, 424-432 (2015)

9. M.S. Joo, D.W. Suh, J.H. Bae, N.S. Mourino, R. Petrov, L.A.I. Kestens, H.K.D.H. Bhadeshia, Experiments to separate the effect of texture on anisotropy of pipeline steel. Mater. Sci. Eng. A 556, 601-606 (2012)

10. K. Zhu, D. Barbier, T. Iung, Characterization and quantification methods of complex BCC matrix microstructures in advanced high strength steels. J. Mater. Sci. 48(1), 413-423 (2013)
11. P. Van Houtte, L. Delannay, I. Samajdar, Quantitative prediction of cold rolling textures in low-carbon steel by means of the LAMEL model. Texture Stress Microstruct. 31(3), 109-149 (1999)

12. A. Das, Calculation of crystallographic texture of BCC steels during cold rolling. J. Mater. Eng. Perform. 26(6), 2708-2720 (2017)

13. X. Wan, K. Wu, G. Huang, R. Wei, In-situ observations of the formation of fine-grained mixed microstructures of acicular ferrite and bainite in the simulated coarse-grained heated-affected zone. Steel Res. Int. 85(2), 243-250 (2014)

14. A.-F. Gourgues, H.M. Flower, T.C. Lindley, Electron backscattering diffraction study of acicular ferrite, bainite, and martensite steel microstructures. Mater. Sci. Technol. 16(1), 26-40 (2000)

15. S.F. Di Martino, G. Thewlis, Transformation characteristics of ferrite/carbide aggregate in continuously cooled, low carbonmanganese steels. Metall. Mater. Trans. A 45(2), 579-594 (2014)

16. T. Watanabe, Grain boundary design and control for high temperature materials. Mater. Sci. Eng. A 166(1-2), 11-28 (1993)

17. A. Das, Fracture complexity of pressure vessel steels. Philos. Mag. 97(33), 3084-3141 (2017)

18. A. Grajcar, W. Zalecki, P. Skrzypczyk, A. Kilarski, A. Kowalski, S. Kolodziej, Dilatometric study of phase transformations in advanced high-strength bainitic steel. J. Therm. Anal. Calorim. 118(2), 739-748 (2014)

19. S. Tsurekawa, S. Nakamichi, T. Watanabe, Correlation of grain boundary connectivity with grain boundary character distribution in austenitic stainless steel. Acta Mater. 54(13), 3617-3626 (2006)

20. D.G. Brandon, The structure of high-angle grain boundaries. Acta Metall. 14(11), 1479-1484 (1966)

21. A.G. Haynes, W. Steven, The temperature of formation of martensite and bainite in low-alloy steel. J. Iron Steel Inst. 183, 349359 (1956)

22. K.W. Andrews, Empirical formulae for the calculation of some transformation temperatures. J. Iron Steel Inst. 203, 721-727 (1965)

23. K. Suzuki, Neutron irradiation embrittlement of ASME SA508, C1. 3 steel. J. Nucl. Mater. 108, 443-450 (1982)

24. K. Suzuki, I. Kurihara, T. Sasaki, Y. Koyoma, Y. Tanaka, Application of high strength MnMoNi steel to pressure vessels for nuclear power plant. Nucl. Eng. Des. 206(2-3), 261-277 (2001)

25. C.J. Duffy, Modelling the electron beam welding of nuclear reactor pressure vessel steel (University of Cambridge, Cambridge, 2014)

26. H.K.D.H. Bhadeshia, J.W. Christian, Bainite in steels. Metall. Trans. A 21(3), 767-797 (1990)

27. X. Liang, A.J. DeArdo, A study of the influence of thermomechanical controlled processing on the microstructure of bainite in high strength plate steel. Metall. Mater. Trans. A 45(11), 5173$5184(2014)$

28. I.W. Chen, Y.H. Chiao, K. Tsuzaki, Statistics of martensitic nucleation. Acta Metall. 33(10), 1847-1859 (1985)

29. A. Das, Crystallographic variant selection of martensite at high stress/strain. Philos. Mag. 95(20), 2210-2227 (2015)

30. A. Das, Crystallographic variant selection of martensite during fatigue deformation. Philos. Mag. 95(8), 844-860 (2015)

31. A. Das, Spatial martensite. Mater. Sci. Eng. A 658, 484-489 (2016)

32. J. Wang, S. van der Zwaag, Z. Yang, H.S. Fang, Aspect ratio of bainite in steels. Mater. Lett. 45(3-4), 228-234 (2000)

33. L. Lan, X. Kong, C. Qiu, Characterization of coarse bainite transformation in low carbon steel during simulated welding thermal cycles. Mater. Charact. 105, 95-103 (2015)

34. S.G. Druce, G. Gage, G. Jordan, Effect of ageing on properties of pressure vessel steels. Acta Metall. 34(4), 641-652 (1986)

35. J.R.C. Guimarães, P.R. Rios, Spatial aspects of martensite. Metall. Mater. Trans. A 43(7), 2218-2224 (2012) 
36. C.S. Kim, A.D. Rollett, G.S. Rohrer, Grain boundary planes: new dimensions in the grain boundary character distribution. Scr. Mater. 54(6), 1005-1009 (2006)

37. T. Watanabe, S. Tsurekawa, S. Kobayashi, S.I. Yamaura, Structure-dependent grain boundary deformation and fracture at high temperatures. Mater. Sci. Eng. A 410, 140-147 (2005)

38. S. Ratanaphan, D.L. Olmsted, V.V. Bulatov, E.A. Holm, A.D. Rollett, G.S. Rohrer, Grain boundary energies in body-centered cubic metals. Acta Mater. 88, 346-354 (2015)

39. R. Viswanathan, C.L. Bauer, Formation of annealing twins, faceting, and grain boundary pinning in copper bicrystals. Metall. Trans. 4(11), 2645-2650 (1973)

40. S.E. Offerman, N.H. Van Dijk, J. Sietsma, S. Grigull, E.M. Lauridsen, L. Margulies, H.F. Poulsen, M.T. Rekveldt, S. Van der Zwaag, Grain nucleation and growth during phase transformations. Science 298(5595), 1003-1005 (2002)

41. S. Zhao, D. Wei, R. Li, L. Zhang, Effect of cooling rate on phase transformation and microstructure of $\mathrm{Nb}-\mathrm{Ti}$ microalloyed steel. Mater. Trans. 55, 1274-1279 (2014)

42. N. Haghdadi, P. Cizek, H. Beladi, P.D. Hodgson, A novel highstrain-rate ferrite dynamic softening mechanism facilitated by the interphase in the austenite/ferrite microstructure. Acta Mater. 126, 44-57 (2017)

43. P. Lin, G. Palumbo, K.T. Aust, Experimental assessment of the contribution of annealing twins to CSL distributions in FCC materials. Scr. Mater. 36(10), 1145-1149 (1997)

44. A. Das, Revisiting stacking fault energy of steels. Metall. Mater. Trans. A 47(2), 748-768 (2016)

45. V. Randle, Twinning-related grain boundary engineering. Acta Mater. 52(14), 4067-4081 (2004)
46. H. Terasaki, Y.I. Komizo, Morphology and crystallography of bainite transformation in a single prior-austenite grain of lowcarbon steel. Metall. Mater. Trans. A 44(6), 2683-2689 (2013)

47. S. Zaefferer, J. Ohlert, W. Bleck, A study of microstructure, transformation mechanisms and correlation between microstructure and mechanical properties of a low alloyed TRIP steel. Acta Mater. 52(9), 2765-2778 (2004)

48. E. Keehan, L. Karlsson, H.K.D.H. Bhadeshia, M. Thuvander, Electron backscattering diffraction study of coalesced bainite in high strength steel weld metals. Mater. Sci. Technol. 24(10), 1183-1188 (2008)

49. A. Das, Grain boundary engineering: fatigue fracture. Philos. Mag. 97(11), 867-916 (2017)

50. A. Das, Cyclic plasticity induced transformation of austenitic stainless steels. Mater. Charact. 149, 1-25 (2019)

51. J.A. Nucci, R.R. Keller, D.P. Field, Y. Shacham-Diamand, Grain boundary misorientation angles and stress-induced voiding in oxide passivated copper interconnects. Appl. Phys. Lett. 70(10), 1242-1244 (1997)

52. N.L. Peterson, Grain-boundary diffusion in metals. Int. Met. Rev. 28(1), 65-91 (1983)

Publisher's Note Springer Nature remains neutral with regard to jurisdictional claims in published maps and institutional affiliations. 